\title{
The MATEX cohort - a Finnish population register birth cohort to study health effects of prenatal exposures
}

Isabell K. Rumrich ${ }^{1,2^{*}}$ D, Kirsi Vähäkangas ${ }^{3}$, Matti Viluksela ${ }^{1,2}$, Mika Gissler ${ }^{4}$, Heljä-Marja Surcel ${ }^{5}$, Hanna de Ruyter ${ }^{6}$, Jukka Jokinen ${ }^{2}$ and Otto Hänninen ${ }^{2}$

\begin{abstract}
Background: The prevalence of chronic diseases, such as immune, neurobehavioral, and metabolic disorders has increased in recent decades. According to the concept of Developmental Origin of Health and Disease (DOHaD), developmental factors associated with environmental exposures and maternal lifestyle choices may partly explain the observed increase. Register-based epidemiology is a prime tool to investigate the effects of prenatal exposures over the whole life course.

Our aim is to establish a Finnish register-based birth cohort, which can be used to investigate various (prenatal) exposures and their effects during the whole life course with first analyses focusing on maternal smoking and air pollution. In this paper we (i) review previous studies to identify knowledge gaps and overlaps available for cross-validation, (ii) lay out the MATEX study plan for register linkages, and (iii) analyse the study power of the baseline MATEX cohort for selected endpoints identified from the international literature.

Methods/design: The MATEX cohort is a fully register-based cohort identified from the Finnish Medical Birth Register (MBR) (1987-2015). Information from the MBR will be linked with other Finnish health registers and the population register to link the cohort with air quality data. Epidemiological analyses will be conducted for maternal smoking and air pollution and a range of health endpoints.

Discussion: The MATEX cohort consists of 1.75 million mother-child pairs with a maximum follow up time of 29 years. This makes the cohort big enough to reach sufficient statistical power to investigate rare outcomes, such as birth anomalies, childhood cancers, and sudden infant death syndrome (SIDS). The linkage between different registers allows for an extension of the scope of the cohort and a follow up from the prenatal period to decades later in life.
\end{abstract}

Keywords: Register-based epidemiology, Maternal smoking, Air pollution, Finland, Developmental origin of disease

\footnotetext{
*Correspondence: Isabell.Rumrich@thl.fi

1 Department of Environmental and Biological Sciences, University of Eastern

Finland (UEF), Kuopio, Finland

${ }^{2}$ Department of Public Health Solutions, National Institute for Health and

Welfare (THL), Kuopio, Finland

Full list of author information is available at the end of the article
} 


\section{Background}

The prenatal and early postnatal period is a time of organ and tissue formation and functional programming, making these periods highly susceptible for any kind of insult. The concept of Developmental Origin of Health and Disease (DOHaD) stresses the importance of prenatal exposures for diseases later in life [1]. According to this concept, the increase in prevalence of chronic diseases (e.g. respiratory diseases, cardiovascular diseases, metabolic disorders) during the last decades is attributed to developmental aberrations associated with environmental exposures or imbalance in nutrition during pregnancy [2]. Although the DOHaD concept was originally developed with a focus on nutrition during pregnancy, it soon was applied also to toxicology and environmental health [1]. The prenatal exposure to diethylstilbestrol (DES), an artificial oestrogen and prescribed from 1940 to 1971 to millions of women during pregnancy to reduce miscarriage, is one of the earliest cases where prenatal exposure to a chemical was linked with serious health effects later in life [1]. The focus on research shifted from teratogenic effects, to effects of low-dose exposures and epigenetic changes. These epigenetic changes may explain the increase in chronic diseases, such as allergies, asthma and metabolic disorders. Most often effects of prenatal exposures are studied in animal models. Epidemiological studies on the effects of prenatal exposures are very difficult, due to the long followup time to catch chronic diseases which may manifest tens of years after the exposures to etiological factors.

In addition to the sufficiently long follow-up, large birth cohorts are essential to link prenatal exposures to health effects later in life, because most effects are minor or the endpoints rare, such as some birth anomalies or childhood cancers. In order to be able to detect even minor changes, which do not necessarily need to be outside the "healthy" average range, big study sizes are needed. Register based epidemiology allows to utilize large study populations and to follow them even over decades by linking various administrative registers, e.g. on health, social welfare and population. Because prenatal development is the most sensitive period of life for external insults (for reviews see e.g. [3, 4]), the possible health effects of environmental risk facts are first observable and most severe in maternally exposed offspring.

In our MATEX cohort we use the Finnish Medical Birth Register (MBR) to define our study cohort. In addition, by using the personal identification number, introduced in 1964-1968 to all Finnish citizens and permanent residents, we link our cohort with the information available in other health and population registers. Health registers have a long tradition in Finland with the earliest registers established in the 1950's [5]. Finnish registers are regularly used in research. Between 2010 and 2016 in total 962 authorisations for data use were given by the National Institute for Health and Welfare (THL), the main holder of health registers in Finland during that period.

The MBR is frequently used in research for a wide range of topics (see Additional file 1, Chapter 3. Examples of use of MBR data in published research). Most commonly birth outcomes, such as birth weight, small for gestational age and preterm birth are used from the MBR. Other risk factors and health endpoints analysed with MBR data, include for example socioeconomic status $[6,7]$, maternal age $[8,9]$, reproductive history [10], stillbirth and neonatal mortality [11, 12], and neurodevelopmental disorders $[13,14]$. The MBR data are not always used for identification of the study population or endpoints of interest, but also to identify confounding factors [15]. The maternal smoking status has been retrieved from the MBR in several studies [16-19]. Although several studies analysed birth cohorts from the MBR born between 1990 and 2010, only one birth cohort from the MBR born after 2010 has been analysed, which aimed at the maternal age at which risk for adverse pregnancy outcomes increases [20], and only one study included children born before 1990, focusing on the effect of socioeconomic status on the incidence of placental abruption [7]. No study investigated the effects of exposure to air pollution or other environmental risk factors during pregnancy on pregnancy outcomes in a Finnish birth cohort.

\section{Maternal smoking}

Maternal smoking during pregnancy is the largest preventable factor posing a risk to the health of the mother and the child. The most severe complication associated with prenatal tobacco smoke is sudden infant death syndrome [21]. Additionally, smoking causes premature birth, low birth weight, and being small for gestational age, which all increase the risk for perinatal mortality. Nicotine, the chemical causing the addictive properties of tobacco, cause abnormal lung development in utero, which has effects throughout the life of the exposed child [22]. As a known teratogen, tobacco smoke is associated with congenital anomalies [23]. Tobacco smoke contains hundreds of chemicals, some of which are known carcinogens. In a meta-analysis it was shown that smoking during pregnancy increases the risk for brain and nervous system tumours in the childhood of the offspring [24]. Despite these well-established consequences of maternal smoking, the fraction of pregnant women smoking remained stable at around 15\% in Finland from 1987 until today.

Since 1990 the smoking status of the mother is recorded in the Finnish MBR during the 1st trimester and at the end of the pregnancy, providing an excellent 
basis for a birth cohort focusing on the effects of maternal smoking. From 1987 to 1990 the smoking status was collected as non-smoker and below/above 10 cigarettes per day. Only a limited number of studies [8, 17, 25] have used the MBR for the analyses of the effects of maternal smoking during pregnancy on the infant (Fig. 1). These studies did not include children born after 2010 and the analyses mostly focused on low birth weight, premature birth and small for gestational age. Only one study [17] analysed major congenital malformations as part of their study. There is a clear knowledge gap in the contribution of maternal smoking to specific congenital malformations, childhood cancer and other morbidities in mother and child.

\section{Prenatal exposure to air pollution}

The possible linkage of Finnish registers has great potential to be used in the future for the investigation of the effects of prenatal ambient air pollution on the health of infants and later in life. Ambient particulate matter (PM) pollution is by far the most significant environmental risk factor for disease and mortality both in Finland and globally. Although health effects of exposure to PM have been thoroughly studied in the adult and elderly population, the effects of prenatal exposures are not as well established. The exposure to $\mathrm{PM}_{2.5}$ has been associated with for example low birth weight in full term babies [26], preterm birth [27] and congenital abnormalities [28]. Only a limited number of studies analysed the effects of low concentration ambient PM $\left(<10 \mu \mathrm{g} / \mathrm{m}^{3}\right)$
[27]. The ambient PM concentration in Finland is well below the annual WHO limit of $10 \mathrm{mg} / \mathrm{m}^{3}$ for $\mathrm{PM}_{2.5}$. The population weighted 3-year mean (2011-2013) based on nine (sub)urban monitoring stations was $6.6 \mu \mathrm{g} / \mathrm{m}^{3}$ of $\mathrm{PM}_{2.5}$ [29]. There is a knowledge gap of the impact of prenatal exposure to low level ambient air pollution, especially for health endpoints other than low birth weight and premature birth. The Finnish MBR has not yet been used to study the effects of low level air pollution exposure during pregnancy on pregnancy outcomes and the health of the offspring later in life.

\section{Study design and methods \\ Aims/objectives}

The overall objectives of the MATEX project is the development of a framework to link a birth cohort identified from the Finnish Medical Birth Register with information from other (health) registers for analyses of prenatal exposures and their related health outcomes over the whole life course. The register-based design will allow for lifelong follow-up for the identification of critical exposure time windows and health effects, which become only apparent in later adulthood.

In the initial proof-of-concept analyses we will look at the effects of prenatal exposure to maternal smoking and probably to some extent to air pollution on pregnancy outcomes, congenital anomalies, childhood cancer, and childhood asthma. In this paper we (i) conduct a review of previous studies to identify knowledge gaps and overlaps available for cross-validation, (ii) lay

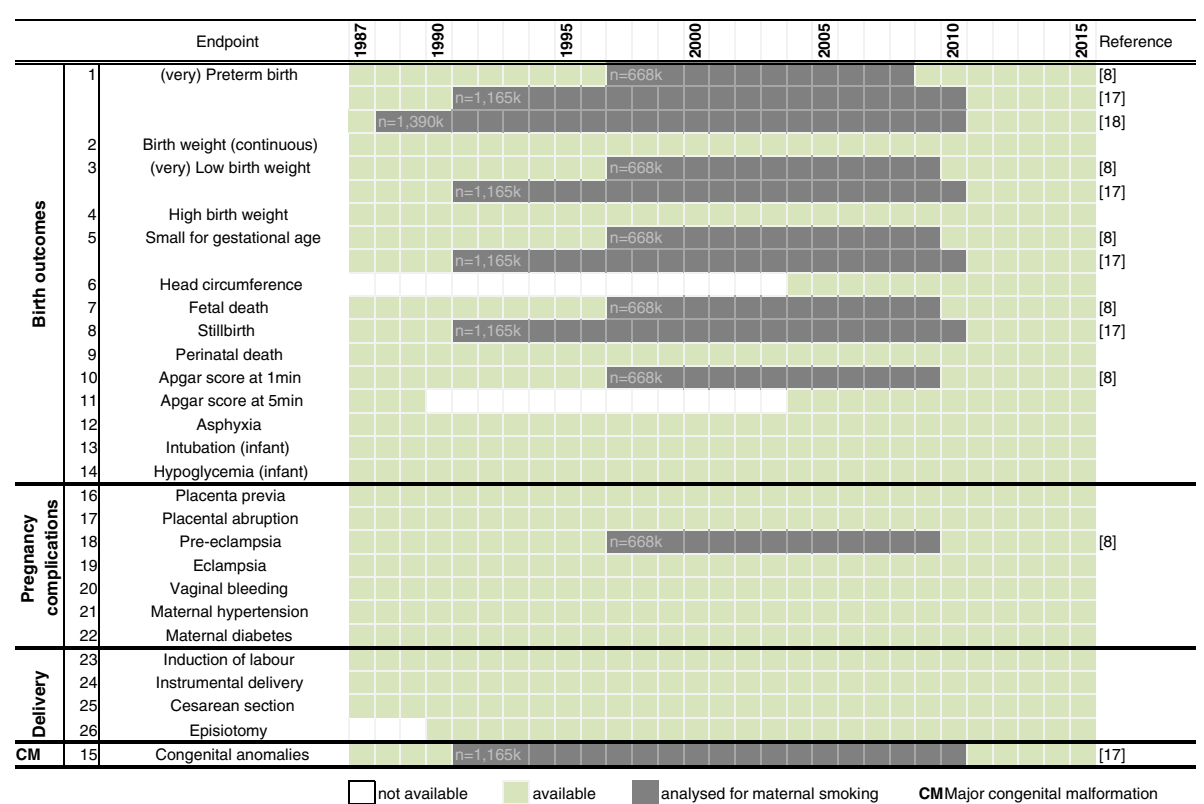

Fig. 1 Health endpoints available in the Medical Birth Register. Annual availability of health endpoints potentially useful for the analyses of the effects of maternal smoking and air pollution. White space means that the data are not available for the year and grey marking means that the data have been analysed previously for the effects of maternal smoking 
out the MATEX study plan for register linkages, and (iii) analyse the study power of the baseline MATEX cohort for selected endpoints identified from the international literature.

\section{The MATEX birth cohort}

The MATEX birth cohort is identified from the Finnish Medical Birth Register (MBR) [30]. The baseline MATEX birth cohort consists of all births recorded in the MBR between 1st January 1987 and 31st December 2015. The MATEX cohort includes personal information of the mother, such as occupation, citizenship, marital status and municipality of residence. Additionally, information on past reproductive history is available: number of previous ectopic pregnancies, miscarriages induced abortions and whether she had a Caesarean section before. The main birth outcomes are recorded: gestational age at birth, birth weight, birth length, head circumference, 1 and 5 min Apgar score, sex of the child and whether the child is born alive or dead. In addition, diagnoses are available as ICD codes (1987-1995 as ICD-9 and 1996-2015 as ICD-10), as well as information on risk factors, such as smoking and gestational diabetes or hypertension, related to pregnancy and medical treatments, e.g. drugs during pregnancy. The risk factors and treatments, which are not recorded as ICD codes are recorded as binary variable (yes/no). The sub-dataset about delivery characteristics includes only binary and categorical information for confounding analyses. Amongst other, it includes the place of birth (hospital, on the way to hospital, home), the mode of delivery, induction of labour, and procedures associated with delivery. Some of the variables have been introduced to the MBR between 1990 and 2004. See Additional file 1 for a detailed overview of the available variables (see 161 Additional file 1, Chapter 1. Data availability in the Medical Birth Register).

The MATEX baseline cohort encompassed 1,745,980 children born in a 29 year period (1987-2015), resulting in about 27.5 million person-years. The average annual number of births during that period was around 60,000 children. The average birth rate in the Finnish population was $1.2 \%$. The majority of mothers in the MATEX cohort were Finnish, multiparous, and married or in a registered partnership. The average maternal age was 29 years (25th-75th percentile: $26-33$ years). Children were on average born at $39+5$ weeks + days gestation with a birth weight of $3.5 \mathrm{~kg}$ and a head circumference of $35 \mathrm{~cm}$. The majority if children had an Apgar score of 9 or 10 at $5 \mathrm{~min}$. Almost all deliveries were in hospital with a majority being a spontaneous vaginal birth (Table 1). For 1.2 million mothers the socioeconomic classification based on occupation is available. Around one third (34\%) of all mothers was lower level employees
Table 1 Characteristics of mother-child pairs of the MATEX cohort

\begin{tabular}{|c|c|c|}
\hline Characteristic & $\begin{array}{l}\text { Available } \\
\text { years** }\end{array}$ & $\begin{array}{l}n(\%) \text { or mean } \\
\text { (25th-75th percentile) }\end{array}$ \\
\hline \multicolumn{3}{|l|}{ Mother } \\
\hline Age [years] & & $29(26-33)$ \\
\hline Pre-pregnancy weight [kg] & 2004-2015 & $67(57-73)$ \\
\hline Height $[\mathrm{cm}]$ & 2004-2015) & $166(161-170)$ \\
\hline Primiparous & & 711,208 (41\%) \\
\hline Citizenship & 1990-2015 & \\
\hline Other than Finnish & & $64,730(5 \%)$ \\
\hline Self-reported smoking & 1990-2015 & \\
\hline No & & $1,436,322(84 \%)$ \\
\hline Quitted during 1st trimester & & $68,344(4 \%)$ \\
\hline Continued during 1st trimester & & $198,125(11 \%)$ \\
\hline \multicolumn{3}{|l|}{ Marital status } \\
\hline $\begin{array}{l}\text { Married/registered partnership } \\
\text { or cohabiting }\end{array}$ & & $1,112,771(67 \%)$ \\
\hline \multicolumn{3}{|l|}{ New-born } \\
\hline Sex (Female) & & $853,401(49 \%)$ \\
\hline Gestational age [week + days] & & $\begin{array}{l}39+5 \\
(39+0-40+6)\end{array}$ \\
\hline Birth weight $[\mathrm{kg}]$ & & $3.5(3.2-3.9)$ \\
\hline Head circumference [cm] & 2004-2015 & $35(34-36)$ \\
\hline Apgar score at 5 min & $\begin{array}{l}1987-1989 \\
2004-2015\end{array}$ & \\
\hline $0-6$ & & $17,768(2 \%)$ \\
\hline $7-8$ & & $72,137(10 \%)$ \\
\hline $9-10$ & & $666,492(88 \%)$ \\
\hline Stillborn & & $6638(0.4 \%)$ \\
\hline $\begin{array}{l}\text { Infant mortality (0-364 days of } \\
\text { age; excluding stillbirths) }\end{array}$ & & $6410(0.4 \%)$ \\
\hline \multicolumn{3}{|l|}{ Number of foetuses } \\
\hline Singletons & & $1,696,181(97 \%)$ \\
\hline Multiples & & $49,797(3 \%)$ \\
\hline \multicolumn{3}{|l|}{ Delivery } \\
\hline Place of birth & 1990-2015 & \\
\hline On the way to hospital & & $1225(0.1 \%)$ \\
\hline Outside hospital (planned) & & $332(0.02 \%)$ \\
\hline $\begin{array}{l}\text { Outside hospital (unplanned/ } \\
\text { no information) }\end{array}$ & & $1126(0.1 \%)$ \\
\hline \multicolumn{3}{|l|}{ Mode of delivery } \\
\hline Vaginal & & $1,336,572(77 \%)$ \\
\hline Breech, vaginal birth & & $10,186(1 \%)$ \\
\hline Vacuum & & $110,361(6 \%)$ \\
\hline Planned caesarean section & & $110,014(6 \%)$ \\
\hline $\begin{array}{l}\text { Urgent/Emergency caesarean } \\
\text { section }\end{array}$ & & $174,810(10 \%)$ \\
\hline
\end{tabular}

"Given if information is not available for the whole period (1987-2015) 
with administrative and clerical occupations. Together less than a third of the mothers are either upper level employees with administrative, managerial, professional and related occupations (14\%) or manual worker (14\%). The remaining mothers are students $(8 \%)$, self-employed $(2 \%)$ or pensioners and un-employed (1\%).

A general overview of the health status of the mother-child pairs are shown in the supplement in the form of incidence of chosen diseases occurring in the perinatal phase as well as congenital anomalies (see Additional file 1: Chapter 3).

\section{Design of register linkages}

The baseline MATEX cohort from the MBR will be supplemented with data from other health registers, as well as an exposure database, consisting of registers for exposure linkage such as the Population Register (Fig. 2, Table 2). All data will be pooled for analyses of exposure response relationships.

The linkage of various registers via the personal identification number (PIN) of the child enables the follow-up of the health history of the children after birth. Linkage with the Register of Congenital Malformations [31] and the Cancer Register [32] helps to identify all children of the baseline cohort, who were born with congenital anomalies, birth defects or who develop cancer later in life. The Care Register for Health Care (HILMO) [33], the Register of Primary Health Care Visits (AvoHILMO) [34] (nationwide coverage since 2011), and the Register of Reimbursement for Prescription Medicines [35] allows to identify cases of specific disorders or diseases later in life, for example asthma. The Cause-of-Death Register facilitates the possibility to study mortality associated with prenatal exposures [36]. Possible linkage with the Population Register [37] can provide the home address history of each mother-child pair, which will be used to link the cohort with air quality data for the investigation of effects of prenatal exposure to air pollution. The register-based design potentially allows for lifelong follow-up for the identification of critical exposure time windows and health effects, which become only apparent in later adulthood.

Different health registers can be used to follow the health status of the children throughout life (Fig. 3). The MBR is the main information source for the health of mother and child during pregnancy and up to the first week of life. In cases of induced abortion, no information is available in the MBR, but under the women's PIN in the Register for Induced Abortions [38]. Induced abortions for social reasons are legally allowed until gestational week 20 and for medical reasons until gestational week 24. All live births and stillbirth from week 22 or with a minimum foetal weight of $500 \mathrm{~g}$ are recorded in the MBR, no matter if the foetus is stillborn or alive. Pregnancy-terminations at weeks 22-24 weeks are not to be reported to the MBR. Pregnancy loss before this milestone is legally considered to be a spontaneous abortion and the event is recorded under the women's PIN in HILMO/AvoHilmo. A live born child receives his/her PIN at birth.

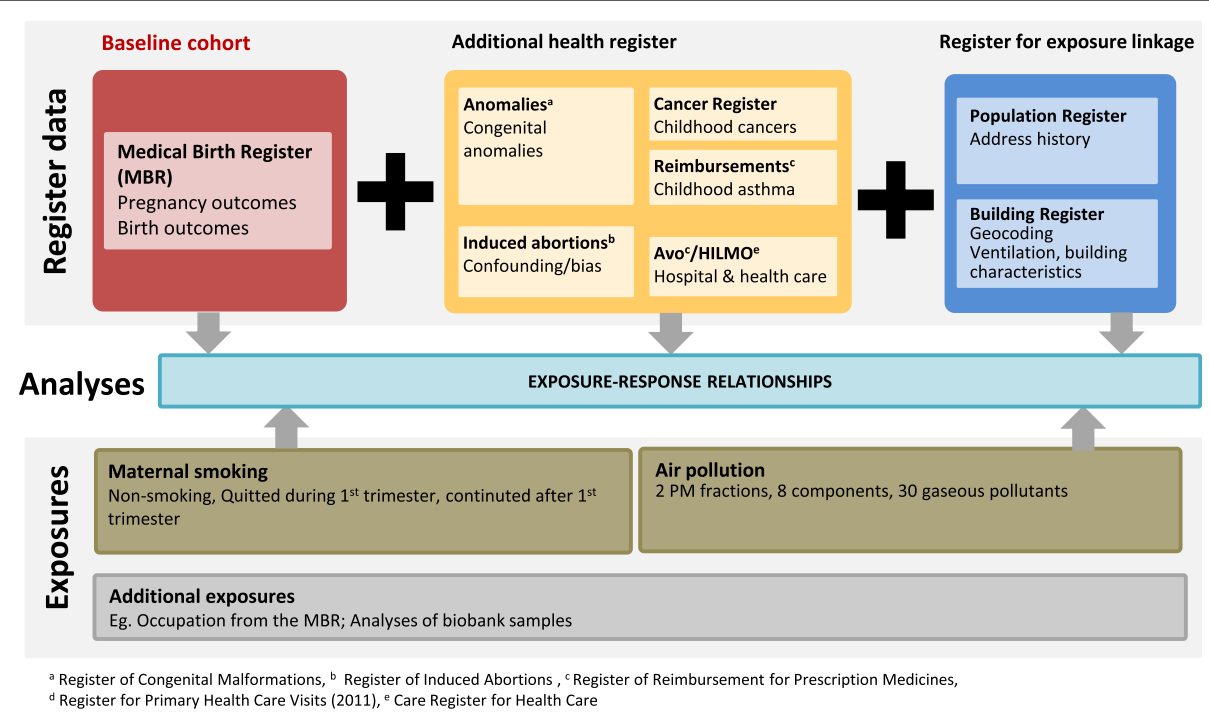

Fig. 2 Schematic description of the planned register linkage of the MATEX cohort. The Matex cohort is recruited from the MBR with other registers for the two proof-of-concept case studies. Registers are linked via mother's personal identification number (PIN) (for the Population Register) or the child's PIN (all other registers). The main exposures targeted will be maternal smoking and air pollution. The main endpoints will be birth outcomes, childhood asthma, childhood cancer and congenital anomalies 
Table 2 The Finnish registers and their data content used in the MATEX project

\begin{tabular}{|c|c|c|c|}
\hline Register & Data available & Register holder & Ref. \\
\hline Medical Birth Register & $\begin{array}{l}\text { Mother's health data (incl. Smoking habits prior to and } \\
\text { during pregnancy, other risk factors, interventions), } \\
\text { pregnancy, delivery, live and stillbirths, GD, BMI, infant } \\
\text { health data by age of } 7 \text { days }\end{array}$ & THL & [30] \\
\hline Register of Induced Abortions & $\begin{array}{l}\text { Data on mother, indication for induced abortion, } \\
\text { diagnoses }\end{array}$ & THL & [38] \\
\hline Register of Congenital Malformations & $\begin{array}{l}\text { Mother's health data, pregnancy, foetus/child, } \\
\text { congenital anomalies and birth defects, diagnoses } \\
\text { (ICD codes) }\end{array}$ & THL & {$[31]$} \\
\hline Care Register for Health Care & Data from hospitals and special health care, diagnoses & THL & [33] \\
\hline Register of Primary Health Care Visits & $\begin{array}{l}\text { Data outpatient health care visits, diagnoses } \\
\text { (available since 2011) }\end{array}$ & THL & [34] \\
\hline Cancer Register & $\begin{array}{l}\text { Persons with cancer, data on cancer type and death } \\
\text { certificate }\end{array}$ & THL & [32] \\
\hline Cause-of-Death Register & Causes of death, death certificates & Statistics Finland & [36] \\
\hline $\begin{array}{l}\text { Register of reimbursements for } \\
\text { Prescription Medicines }\end{array}$ & $\begin{array}{l}\text { Purchases of prescription medication eligible for } \\
\text { reimbursement }\end{array}$ & KELA ${ }^{a}$ & [35] \\
\hline Finnish Maternity Cohort & $\begin{array}{l}\text { Serum bank, data on mother, sampling date, } \\
\text { expected due date, previous pregnancies }\end{array}$ & $\mathrm{THL}^{\mathrm{b}}$ & [42] \\
\hline Population Register & Address history & $\begin{array}{l}\text { Population } \\
\text { Register Center }\end{array}$ & [37] \\
\hline
\end{tabular}

${ }^{a}$ Finnish Social Security Institution; ${ }^{b}$ From June 2017 the samples will be transferred to the Biobank Borealis of Northern Finland, established and maintained by the Northern Ostrobothnia Hospital District, the University of Oulu, NordLab and the hospital/healthcare districts of Lapland, Länsi-Pohja, Central Ostrobothnia and Kainuu

\section{Statistical power of the MATEX cohort}

The statistical power of the MATEX cohort was estimated using $\mathrm{R}$ software epiR package. The smallest detectable relative risk (RR) was computed for an analyses using 95\% confidence interval and a study power of $90 \%$. The smallest detectable RR was calculated for a range of incidence rates and exposure rates for the total MATEX cohort, as well as the part of the cohort, born 2004 or later, when the latest variables were introduced to the MBR. Additionally, the smallest detectable RR was compared with published RR for outcomes associated with maternal smoking.

For incidence rates between $0.1 \%$ to $50 \%$ the MATEX cohort has reasonable power (Fig. 4) to detect outcomes associated with a wide range of exposures (exposure prevalence $1 \%$ to $30 \%$ ). The total MATEX cohort has $90 \%$ power to detect outcomes with an incidence rate of $0.1 \%$ and a RR $\leq 1.5$ for exposure prevalent in $10 \%$ or more of the MATEX cohort.

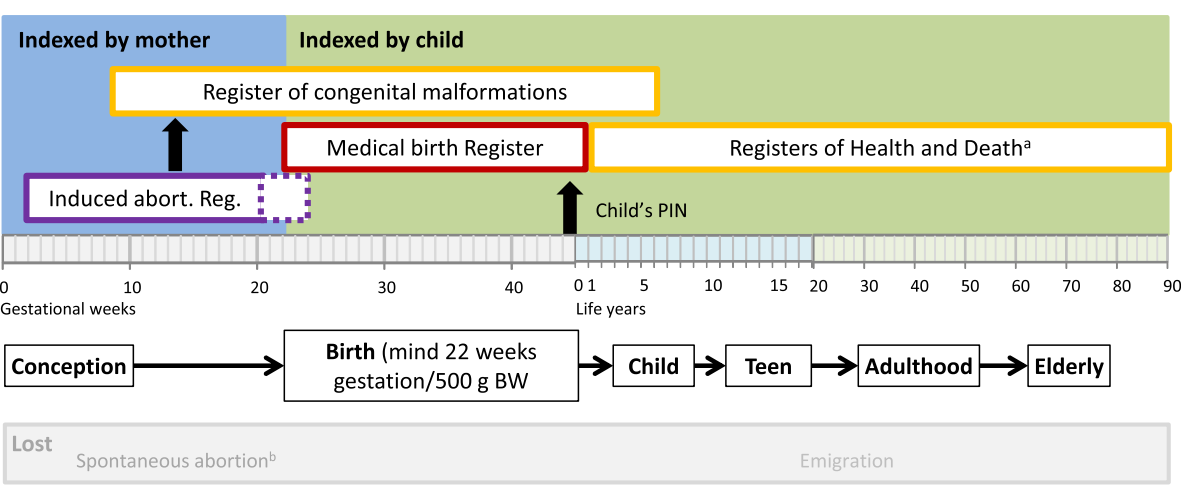

${ }^{a}$ Care Register for Health Care; Register of Primary Health Care Visits; Register of Reimbursement for Prescription Medicines; Register; Cancer Register; Cause-of-Death Register
๖ Partly available from the mother's health care register entries PIN: Personal identification number

Fig. 3 Possibility for life-long follow-up of the health status of the birth cohort by utilizing registers. The cohort can be followed using the personal identification number (PIN) of the child, except of the case of induced abortion (recorded under mother's PIN). In the case of spontaneous abortion the record is partly available from the woman's health register. Emigration outside of Finland causes the loss for follow up of the child 


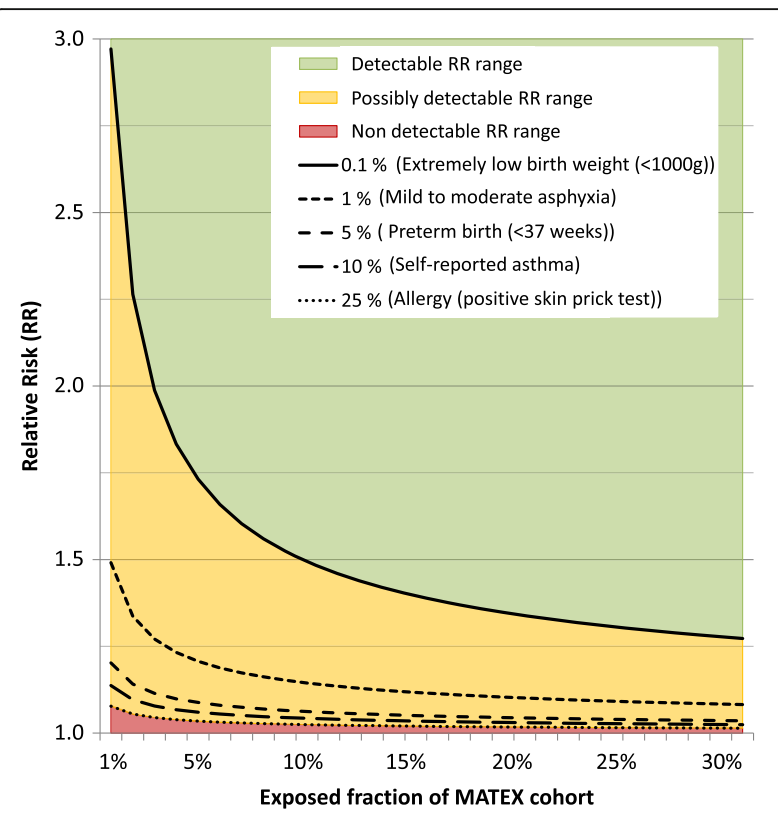

Fig. 4 Minimum detectable $R R$ for risk factors $(R R \geq 1)$ for five incidence rates. The minimum detectable relative risk (RR) has been estimated for five incidence rates $(0.1 \%, 1 \%, 5 \%, 10 \%, 25 \%)$ and a range of an exposed fraction of the MATEX cohort between 1 and $30 \%$. The red area describes RRs not detectable within reasonable exposure prevalence and disease incidence, the yellow area describes RRs possibly detectable depending on exposure prevalence and/or disease incidence, and the green area describes the RRs which can be detected in whole range of exposure prevalence and disease incidence. A study power of $90 \%$ has been assumed

When planning the MATEX cohort, health endpoints associated with maternal smoking (birth outcomes, congenital anomalies, childhood cancer) have been selected based on a literature review and the needed cohort size was estimated [39]. After receiving the data, the chance to detect the reported RRs in the MATEX cohort, has been re-calculated (Fig. 5). Despite the large study population, it seems unlikely that the cohort has sufficient power to result in statistically significant risk estimates for most congenital anomalies and childhood cancers. The cohort has enough statistical power that statistically significant risk estimates can be expected for the main birth outcomes.

\section{Planned analyses \\ Exposures}

Information on maternal smoking is retrieved from the MBR. The information is collected by the midwife during the antenatal visits. Maternal smoking status is available as four categories: (i) non-smoker, (ii) quitted smoking during first trimester, (iii) continued smoking after the first trimester, or (iv) no information. A preliminary analysis of the smoking status in the MATEX birth cohort suggests that about $15 \%$ of all children are exposed to maternal smoking at some point of the pregnancy without any trend during the study period (1987 to 2015). However, the fraction of women quitting smoking during the first trimester is increasing during the last decades. Additionally, smoking prevalence is higher in mothers younger than 20 years compared to mothers older than 30 years. In a study comparing the MBR smoking information with serum samples analysed for cotinine, the non-disclosure rate of smoking was reported to be $8 \%$ and the rate of inactive smoking mothers was reported to be $5 \%[40]$.

Air pollution exposure can be linked with the mother-child pairs via the home address of the mother during pregnancy. Modelled ambient concentrations data will be available for PM with a diameter of less than $2.5 \mu \mathrm{m}\left(\mathrm{PM}_{2.5}\right)$ and less than $10 \mu \mathrm{m}$ $\left(\mathrm{PM}_{10}\right)$, as well as 30 gaseous components of air pollution. The gaseous components include amongst others carbon dioxide $\left(\mathrm{CO}_{2}\right)$, carbon monoxide $(\mathrm{CO})$, ozone $\left(\mathrm{O}_{3}\right)$, nitrogen dioxide $\left(\mathrm{NO}_{2}\right)$ and sulphur dioxide $\left(\mathrm{SO}_{2}\right)$. The effect of exposure during the whole pregnancy, the three trimesters separately, and the last week of pregnancy can potentially be analysed.

The analyses can be widened by the inclusion of other exposures. The occupational status of the mothers is available as Classification of Occupation [41] and can be analysed for occupation specific risks. It is well established, that some occupations are characterised by specific exposures for examples farmers and pesticides, hair dressers and chemicals, and painters and solvents. The Finnish Maternity Cohort serum samples can be used to assess the exposure to chemicals, such as perfluorinated compounds and organochlorine pesticides [42].

\section{Health outcomes}

The health endpoints of interest have been selected a priori based on a literature review of previous studies. Four main categories of health endpoints will be included in the analyses: (i) pregnancy outcomes, (ii) congenital malformations, (iii) childhood cancer, and (iv) asthma.

As pregnancy endpoints mainly gestational age (preterm birth), birth weight, size for gestational age (small for gestational age, SGA), head circumference and Apgar score will be analysed. The effects of maternal smoking or air pollution on stillbirth and Sudden Infant Death Syndrome (SIDS) will be analysed. Additional analyses will potentially be done for respiratory problems in the infant (diagnoses, need for intubation) and gestational illnesses in the mother (diabetes, hypertension, (pre-)eclampsia).

The effects of prenatal exposures on congenital anomalies will be analysed for all major malformations as a group and specific malformations if the incidence rate 

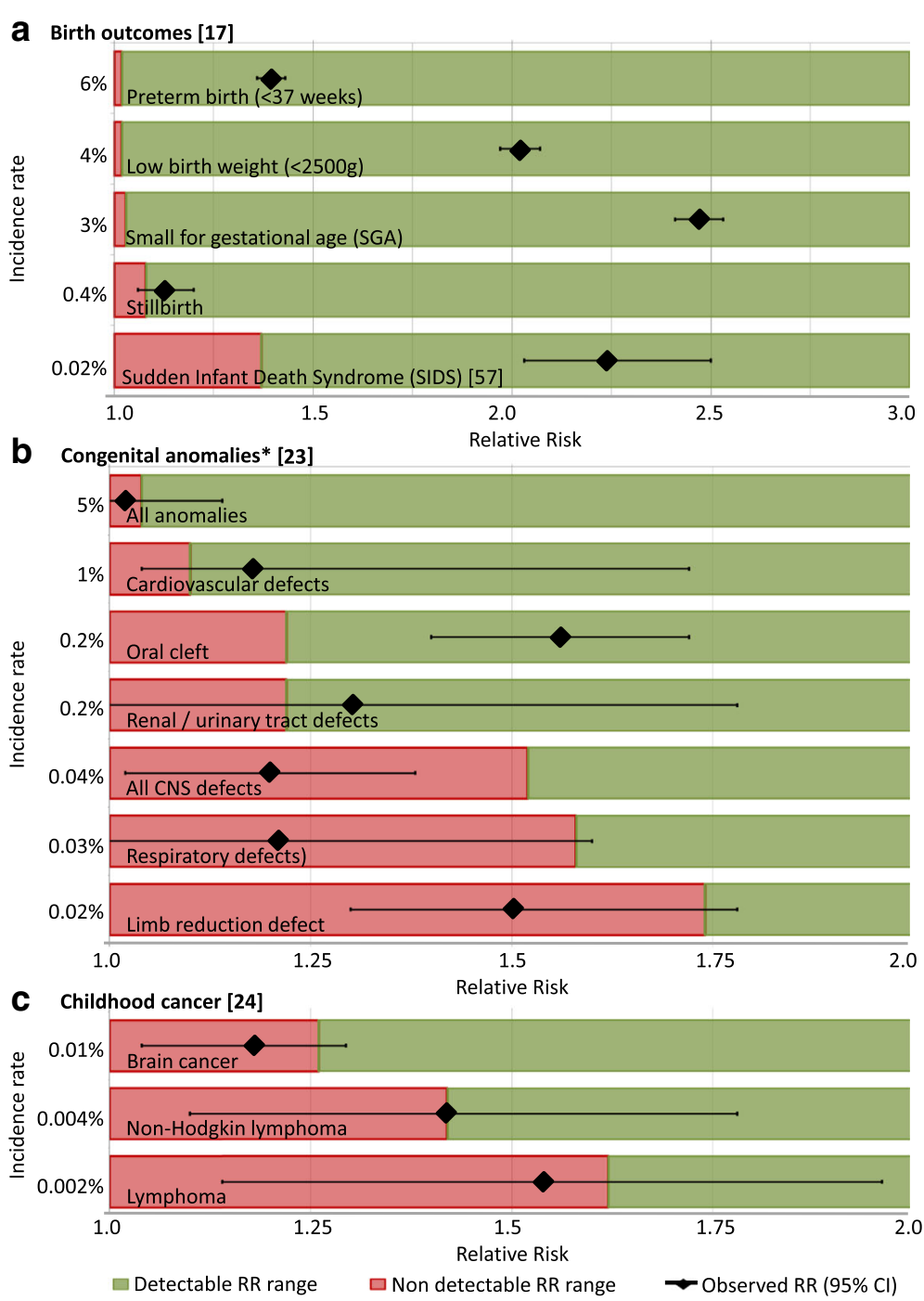

* Congenital anomalies incidence is based on reported cases in the MBR, which misses all cases diagnosed in induced abortions (up to $90 \%$ of all cases)

Fig. 5 Example for the study power of the MATEX cohort and maternal smoking as exposure. The smallest detectable RR in the MATEX cohort in (study power $=90 \%$ ) is compared with RR, which have been reported for birth outcomes (Panel a), congenital anomalies (Panel b) and childhood cancer (Panel c) $[23,57]$

is high enough for sufficient study power. For minimum estimates if the incidence rates, see Additional file 1: Table S2. Congenital malformation analyses will include physical anomalies as well as chromosomal and genetic anomalies. Down syndrome is of particular interest as a chromosomal anomaly.

Childhood cancer will be included as an endpoint in the analyses if sufficient study power can be reached. Leukaemia is most promising in terms of study power, because it is the most common cancer in childhood. However, the evidence for an association with maternal smoking is limited [24]. The evidence for an association of maternal smoking with brain cancer is stronger, but the incidence rate is lower, limiting the statistical power of the MATEX cohort. It is not expected that enough specific cancer cases are recorded during the study period to confidently expect sufficient study power.

Asthma can be interpreted as a continuum of respiratory problems after birth. Potentially asthma can be defined based on the entitlement for medical reimbursement for asthma medication. Additionally, data are available for diagnoses made in in- or outpatient care from the Care Register of Health Care and the Register of Primary Health Care Visits.

\section{Confounding analyses}

Due to the full register-based design of the MATEX study, only information recorded in the (health) 
register can be used for adjustment for confounding factors. In general, the assumption is that the risk for adverse pregnancy outcomes increases with a maternal age of 35 years. However, for the Finnish population it was reported, that the risk for some pregnancy outcomes increases significantly already in earlier age [20]. This underlines the importance of maternal age as a confounding factor as a continuous variable, and not as a binary variable of younger or older than 35 years.

Socio-economic status is a strong confounding factor. We will use the Finnish Classification of Socioeconomic Groups based on the occupation of the mother recorded in the MBR. The classification is based on eight main socioeconomic groups and was developed in 1989 [43]. The information is available in the MBR since 1990. Socioeconomic status is a strong indicator of health behaviour and dietary habits. Several studies showed that the risk for adverse pregnancy outcomes differs between socioeconomic groups in Finland [6, 7, 25].

Maternal smoking, gestational age, birth weight and diseases during pregnancy are available from the MBR and will be used as confounding factors as appropriate. Gestational age and (not well managed) maternal diabetes heavily affect birth weight. The child's sex, the mother's citizenship and birth order are available from the MBR for confounding analyses.

The effect of the physical location on the exposureresponse relationship can potentially be investigated based on the municipality of residence of the mother during pregnancy. It can be used to assign the degree of urbanisation in the municipality of residence of the mother.

The Finnish health care system divides hospitals into three levels, based on the level of specialised treatment that is offered. Birth in smaller hospitals and less specialised hospitals (level 2 compared to level 3) has been shown to increase the risk for neonatal mortality [11, 12]. Information on the hospital and where each birth in the cohort was given is available and can be used to adjust for the confounding effect of hospital type.

The register-based design limits the ability to adjust for those confounding factors, which are not recorded in the registers. Paternal smoking, for example, is not recorded in any register and therefore cannot be included in any of the analyses. Information on other lifestyle factors (physical activity, diet, alcohol consumption) is not available either. Additionally, some factors, which are important for confounding analyses, such as maternal height and weight, have been introduced to the MBR only in 2004. These limitations need to be taken into account when planning for the various analyses.

\section{Statistical models and possibilities for various analyses}

Due to the various analyses that will be conducted, a detailed description of each of the analyses is not possible within the scope of this paper. However, mainly bivariable analyses will be performed to evaluate statistical differences in variables between exposure groups using the $X^{2}$ test. For continuous variables - as applicable - independent sample $t$ test will be used. Multivariable logistic regression analysis will be performed to calculate RRs or ORs with 95\% CIs between exposure and each adverse perinatal outcome. Depending on the outcome, different statistical methods need to be used. Each analysis will be adjusted to confounding factors as appropriate. The statistical analyses will be done in R statistical software.

The rich dataset allows for analyses of continuous variables (birth weight, gestational age, head circumference) either as a continuous variable or as a categorical variable based on international disease definitions, such as (very) low birth weight and (very) preterm birth. The other variables can only be analysed as categorical or binary variables.

To some extent critical windows of exposure can be investigated. The effects of maternal smoking throughout the whole pregnancy can be compared to the effects of smoking only during the first trimester. The effects of prenatal air pollution can be analysed for average concentration or peak concentration, as well as during different periods of the pregnancy.

In order to estimate the disease burden associated with maternal smoking and air pollution, the Burden of Disease (BoD) will be estimated according to the WHO method [44]. The quantification of the health impact will provide valuable estimates about the magnitude of the health impact, as well as the severity of health endpoint in terms of healthy life lost.

\section{Discussion}

Register-based birth cohorts provide ultimately possibilities to study the effects of prenatal and childhood exposures throughout the life course and to identify sensitive or critical time windows as is already clear from the studies carried out using the Finnish Birth Register $[17,19,20]$. In the current work our special focus is on the early postnatal period with the lifelong follow-up remaining as a readily available option. The linkage of multiple health registers supports comprehensive case identification and follow up. The current baseline cohort size of 1.75 million children leads to high study power, which is sufficient to study even rare endpoints, such as birth malformations and childhood cancer. 


\section{Scientific knowledge gaps and potential of the MATEX birth cohort}

Maternal smoking is an established cause for low birth weight and preterm birth [21]. Nevertheless, there is controversy about the association between maternal smoking and childhood cancers or specific congenital anomalies. These outcomes have low incidence rates requiring big studies to reach sufficient study power. Case-control design is often applied to identify most cases without the need for the big size of a cohort study [45]. Case-control design is retrospective leading potentially to recall bias of exposures during the pregnancy, which may have occurred decades earlier. Additionally, both case-control and cohort designs may be biased in the recruitment of the controls or study population. Register-based approach minimises the potential for both biases [5]. The health registers cover virtually the whole population. Therefore there is no risk that some population groups are over- or under-represented. The use of exposure databases minimises the risk for recall bias.

The fully register-based design limited to the available data, which, in the case of the Finnish Birth Register, have been collected for use over the 29 year recruitment period. It is should be noted that some important confounding variables are missing for certain years, such as maternal height and weight, as well as the socioeconomic group. Additionally, some possibly important confounding factors are not available, for example paternal smoking, alcohol consumption during pregnancy and physical activity. Furthermore, nicotine replacement therapy is potentially important, in the light of the fetotoxicity of nicotine found in animal studies (for a recent review, see [46]). However, it has been used only for a short period and the data has not been systematically collected in the birth register. Overall, except of maternal smoking, no lifestyle information is available. Due to the large cohort size, it is not feasible to collect additional data via questionnaires or interviews. For variables that are temporarily restricted, the cohort can be analysed in two groups (one with adjustment for the variable, one without the adjustment) to investigate the magnitude of the confounding.

Harmful effects of prenatal exposure to cigarette smoke on the 2nd generation include implications of e.g. germ cell mutations in the case of maternal smoking during pregnancy or paternal preconceptional smoking [47], but are not well-established, while the effects of air pollution have not been studied at all. The MATEX cohort is recruited over a long enough time that we can identify potential pregnancies of women, who are included in the cohort at birth. The oldest members of the cohort are currently 29 years old and the mean maternal age at pregnancy is 29 years. Later on the current focus on maternal smoking and air pollution may be widened to other prenatal exposures. The Finnish Maternity Cohort, that contains first trimester serum samples from 2 million pregnant women since 1983 (national coverage 95\% of all pregnancies), as well as other Finnish blood and serum banks can be used for exposure assessment to chemicals [42]. The availability of address history has the potential to investigate exposures emitted from stationary sources, such as (nuclear) power plants, industrially contaminated sites, high voltage power lines or transformer stations (extremely low magnetic fields).

Nordic health registers are to a great extent similar, which opens the possibility for Nordic collaboration to increase the cohort size even further [48]. This would increase the study power in order to investigate rare outcomes associated with low prevalence exposures, such as illegal drugs.

Register-based epidemiology is restricted to data, which are routinely collected in registers. Most registers, however, have not been designed for research purposes per se, but rather for statistical purposes. Hence, some information important and interesting for research is missing. Information on lifestyle is not available, except of maternal smoking in the MBR. No data about paternal smoking or the use of nicotine products, such as chewing gums and skin patches, are available. Additionally, data on alcohol consumption, physical activity, eating habits and other exposures are missing. The data availability limits the possibility to adjust for confounders.

\section{Ethical and legal considerations}

The routine collection of data for health register means more work for the health professionals, who collect the data, as well as costs to collect the data and maintain the register. These costs are paid by public funding. Utilizing data that is collected and stored anyway is cost-efficient. There is an ethical duty of the society to use the available data to improve public health and the health services. Utilization of the data not only for statistics, but also research, justifies the increased work load and costs to maintain the register. Because individuals barely have a chance to voice their opinion whether they want their data to be collected or to be used in research, the research community should do its best to make use of the data in a responsible way, not only for science, but especially to improve public and health services for the individuals. Additionally, the scientific community has the ethical responsibility to disseminate the results and conclusions both within the scientific community, and to the general public (e.g. [49]. This means that the results should not only be published in scientific journals, but also in general newspapers and responsible social media in plain language, ensuring that the public benefits, too. 
Finnish and European legislation (Act on the Openness of Government Activities (621/1999) [50]; Section 8.4, Personal Data Act (523/1999) [51]; European level Directive 2016/679 (accepted 27th April 2016, to be implemented by 25 May 2018) [52] regulate the use of personal data for various purposes including research. Generally (Declaration of Helsinki [53]), and according to Finnish law (488/1999) [54] research must be based on the consent of research subjects, unless obtaining consent is unduly difficult and the research cannot be carried out without using the data. In this case the prerequisites set out in the law must be satisfied for an exception from the need for informed consent. The full register-based study design qualifies for such an exemption from the need for informed consent. Besides, the majority of Finnish public considers the benefit for public health more important than the individual right to privacy [55]. However, in the study by Eloranta and Auvinen [55], information about ongoing and new register-based research was deemed inadequate and register-based research was in general seen as an unfamiliar topic. In the MATEX study only coded information without PINs and names are being used, disabling the direct identification of individuals. Additionally, the statistical analyses do not require us to work with data of individuals, but only with the data as a set. The publication plan includes this study protocol, giving the possibility to inform the society how their data will be used. Additionally, the results of the analyses will not only be published in scientific articles, but also in newspaper articles aimed at the general public.

Data protection is crucial when health data are used, because of the importance to protect privacy and inhibit misuse of the data (e.g. $[49,56])$. Individuals may be identified based on their characteristics and health history, even with unidentified data. In human biomedical studies a positive statement from an ethics committee is required by law in Finland $(488 / 1999)$ before filing the request to the register holder for obtaining data. Among the crucial aspects are that data protection is sufficient and that a plan exists, what will be done with the data once the study is finished [5]. For register-based studies, no ethics committee statement is required in Finland.

\section{Conclusions}

Register study designs provide a cost efficient opportunity to study public health impacts of environmental risk factors. In this work we establish a baseline birth cohort and demonstrate its functionality and evaluate it by studying the effects of maternal smoking. The big study size allows observations of small risks associated with common exposures. In addition, it potentially allows the inclusion of rare outcomes and rare exposures. The register-based design makes follow-up and extension of the cohort easy and straight forward. Thus, health effects of foetal exposure over the whole life course can be studied. Exposure data can be linked via home address, serum banks or additionally collected information of the mother-child pairs.

\section{Additional file}

Additional file 1: Supplementary material. (PDF $638 \mathrm{~kb}$ )

\section{Abbreviations}

AvoHILMO: Register of Primary Health Care Visits; DOHaD: Developmental Origin of Health and Disease; HILMO: Care Register for Health Care; MBR: Finnish Medical Birth Register; PIN: Personal Identification Number used in register linkages, replaced by study id in the dataset; $\mathrm{PM}_{10}$ : Particulate matter with a diameter of $\leq 10 \mu \mathrm{m} / \mathrm{m}^{3} ; P_{2.5}$ : Particulate matter with a diameter of $\leq 2.5 \mu \mathrm{m} / \mathrm{m}^{3}$; RR: Relative Risk; THL: National Institute of Health and Welfare

\section{Acknowledgements}

We would like to thank the valuable contribution of experts at Unit of Impact Assessment at THL's Department of Public Health Solutions and technical support at the Register holders.

\section{Funding}

This work was supported by the Juho Vainio Foundation (grant numbers 201,510,322, 201,610,405 and 201,710,136), NordForsk under the Nordic

Programme on Health and Welfare project NordicWelfAir (\#75007), Academy of Finland project BATMAN (285672), the EU Life project Index Air (LIFE15 ENV/PT/000674), and intramural funding by the participating institutes and intramural funding of the institutions.

\section{Availability of data and materials}

The data supporting the findings of this study have been obtained from the Finnish National Institute of Health and Welfare, who is the holder of the Medical Birth Register, and used under license for the current study, and so are not publicly available. The data cannot be made available to ensure privacy protection of the cohort members.

\section{Authors' contributions}

IKR, KV, MV, OH, HMS, MS, JJ contributed to the design of the study. IKR and $\mathrm{OH}$ selected the variables and requested data from the register holder. IKR $\mathrm{KV}, \mathrm{MV}, \mathrm{OH}, \mathrm{HdR}, \mathrm{MG}$ were major contributor in writing the manuscript and securing funding for the project. IKR performed the preliminary analyses of data. MG and HMS expertise in register research as well as HdR medical expertise contributed the design of the study. All authors read, revised and approved the manuscript.

\section{Ethics approval and consent to participate}

In accordance with the Finnish Medical Research Act (1999/488) the MATEX study including the birth cohort identified from the MBR has been approved by the ethics committee of the Northern Ostrobothnia Hospital District (EETTMK 44/2016; issued 18th April 2016). The right to use of register data hold by the National Institute for Health and Welfare was granted under the document number THL/838/6.02.00/2016 (issued 22nd June 2016). The study design is fully register-based. The individual-level data are coded and the key for the coding is in the stored by the register holder. The dataset is stored on a secured network drive, which can only be accessed by authorised persons listed in the ethical approval and approval by the register holder. Due to the full register-based design of the study, no informed consent is required from the study participants according to Directive 2016/679 and European level Directive 2016/679. 


\section{Competing interests}

The authors declare that they have no competing interests.

\section{Publisher's Note}

Springer Nature remains neutral with regard to jurisdictional claims in published maps and institutional affiliations.

\section{Author details}

${ }^{1}$ Department of Environmental and Biological Sciences, University of Eastern Finland (UEF), Kuopio, Finland. '2Department of Public Health Solutions, National Institute for Health and Welfare (THL), Kuopio, Finland. ${ }^{3}$ University of Eastern Finland (UEF), School of Pharmacy/Toxicology, Kuopio, Finland. ${ }^{4}$ Department of Information Services, National Institute for Health and Welfare, Helsinki, Finland. ${ }^{5}$ Department of Welfare, National Institute for Health and Welfare, Oulu, Finland. '6Southern Osthrobothnia Central Hospital, Seinäjoki, Finland.

Received: 10 July 2017 Accepted: 26 October 2017

Published online: 07 November 2017

\section{References}

1. Haugen AC, Schug TT, Collman G, Heindel JJ. Evolution of DOHaD: the impact of environmental health sciences. J Dev Orig Health Dis. 2015;6(2):55-64

2. Barouki R, Gluckman PD, Grandjean P, Hanson M, Heindel JJ. Developmental origins of non-communicable disease: implications for research and public health. Environ Health. 2012;11:42. doi:10.1186/1476-069X-11-42.

3. Anderson LM. Environmental genotoxicants/carcinogens and childhood cancer: bridgeable gaps in scientific knowledge. Mutat Res. 2006;608(2):136-56.

4. Tilson HA. The concern for developmental neurotoxicology: is it justified and what is being done about it? Environ Health Perspect. 1995;103(Suppl 6):147-51.

5. Gissler M, Haukka J. Finnish health and social welfare registers in epidemiological research. Norsk Epidemiologi. 2004;14(1):113-20.

6. Raisanen S, Cartwright R, Gissler M, Kramer MR, Heinonen S. The burden of OASIS increases along with socioeconomic position-register-based analysis of 980,733 births in Finland. PLoS One. 2013;8(8):e73515.

7. Raisanen S, Gissler M, Nielsen HS, Kramer MR, Williams MA, Heinonen S. Social disparity affects the incidence of placental abruption among multiparous but not nulliparous women: a register-based analysis of 1,162,126 singleton births. Eur J Obstet Gynecol Reprod Biol. 2013;171(2):246-51.

8. Lamminpää R: Advanced maternal age, pregnancy and birth. PhD. University of Eastern Finland, 2015.

9. Klemetti R, Gissler M, Sainio S, Hemminki E. Associations of maternal age with maternity care use and birth outcomes in primiparous women: a comparison of results in 1991 and 2008 in Finland. BJOG. 2014;121(3):356-62.

10. Klemetti R, Gissler M, Niinimaki M, Hemminki E. Birth outcomes after induced abortion: a nationwide register-based study of first births in Finland. Hum Reprod. 2012;27(11):3315-20.

11. Rautava L, Lehtonen L, Peltola M, Korvenranta E, Korvenranta H, Linna M, Hallman M, Andersson S, Gissler M, Leipala J, Tammela O, Hakkinen U. PERFECT preterm infant study group: the effect of birth in secondary- or tertiary-level hospitals in Finland on mortality in very preterm infants: a birth-register study. Pediatrics. 2007;119(1):e257-63.

12. Karalis E, Gissler M, Tapper AM, Ulander VM. Effect of hospital size and on-call arrangements on intrapartum and early neonatal mortality among low-risk newborns in Finland. Eur J Obstet Gynecol Reprod Biol. 2016;198:116-9.

13. Malm H, Artama M, Brown AS, Gissler M, Gyllenberg D, Hinkka-YliSalomaki S, McKeague I, Sourander A. Infant and childhood neurodevelopmental outcomes following prenatal exposure to selective serotonin reuptake inhibitors: overview and design of a Finnish register-based study (FinESSI). BMC Psychiatry. 2012;12:217. doi:10.1186/1471-244X-12-217.

14. Polo-Kantola P, Lampi KM, Hinkka-Yli-Salomaki S, Gissler M, Brown AS, Sourander A. Obstetric risk factors and autism spectrum disorders in Finland. J Pediatr. 2014;164(2):358-65.

15. Nohynek H, Baum U, Syrjanen R, Ikonen N, Sundman J, Jokinen J. Effectiveness of the live attenuated and the inactivated influenza vaccine in two-year-olds - a nationwide cohort study Finland, influenza season 2015/16. Euro Surveill. 2016;21(38) doi:10.2807/1560-7917.ES.2016 21.38.30346.

16. Leivonen S, Chudal R, Joelsson P, Ekblad M, Suominen A, Brown AS, Gissler M, Voutilainen A, Sourander A. Prenatal maternal smoking and Tourette syndrome: a Nationwide register study. Child Psychiatry Hum Dev. 2016;47(1):75-82.

17. Raisanen S, Sankilampi U, Gissler M, Kramer MR, Hakulinen-Viitanen T, Saari J, Heinonen S. Smoking cessation in the first trimester reduces most obstetric risks, but not the risks of major congenital anomalies and admission to neonatal care: a population-based cohort study of 1,164,953 singleton pregnancies in Finland. J Epidemiol Community Health. 2014;68(2):159-64.

18. Raisanen S, Vehvilainen-Julkunen K, Gissler M, Heinonen S. Smoking during pregnancy is associated with a decreased incidence of obstetric anal sphincter injuries in nulliparous women. PLoS One. 2012;7(7):e41014.

19. Tran PL, Lehti V, Lampi KM, Helenius H, Suominen A, Gissler M, Brown AS, Sourander A. Smoking during pregnancy and risk of autism spectrum disorder in a Finnish National Birth Cohort. Paediatr Perinat Epidemiol. 2013;27(3):266-74.

20. Klemetti R, Gissler M, Sainio S, Hemminki E. At what age does the risk for adverse maternal and infant outcomes increase? Nationwide register-based study on first births in Finland in 2005-2014. Acta Obstet Gynecol Scand. 2016;95(12):1368-75.

21. Banderali G, Martelli A, Landi M, Moretti F, Betti F, Radaelli G, Lassandro C, Verduci E. Short and long term health effects of parental tobacco smoking during pregnancy and lactation: a descriptive review. J Transl Med. 2015;13:327. doi:10.1186/s12967-015-0690-y.

22. McEvoy CT, Spindel ER. Pulmonary effects of maternal smoking on the fetus and child: effects on lung development, respiratory morbidities, and life long lung health. Paediatr Respir Rev. 2017;21:27-33.

23. Hackshaw A, Rodeck C, Boniface S. Maternal smoking in pregnancy and birth defects: a systematic review based on 173687 malformed cases and 11.7 million controls. Hum Reprod Update. 2011;17(5):589-604.

24. Rumrich IK, Viluksela M, Vahakangas K, Gissler M, Surcel HM, Hanninen O. Maternal smoking and the risk of cancer in early life - a meta-analysis. PLoS One. 2016;11(11):e0165040.

25. Raisanen S, Gissler M, Kramer MR, Heinonen S. Influence of delivery characteristics and socioeconomic status on giving birth by caesarean section - a cross sectional study during 2000-2010 in Finland. BMC Pregnancy Childbirth. 2014;14:120. doi:10.1186/1471-2393-14-120.

26. Pedersen M, Giorgis-Allemand L, Bernard C, Aguilera I, Andersen AM, Ballester F, Beelen RM, Chatzi L, Cirach M, Danileviciute A, Dedele A, Eijsden M, Estarlich M, Fernandez-Somoano A, Fernandez MF, Forastiere F, Gehring U, Grazuleviciene R, Gruzieva O, Heude B, Hoek G, de Hoogh K, van den Hooven EH, Haberg SE, Jaddoe WW, Klumper C, Korek M, Kramer U, Lerchundi A, Lepeule J, Nafstad P, Nystad W, Patelarou E, Porta D, Postma D, Raaschou-Nielsen O, Rudnai P, Sunyer J, Stephanou E, Sorensen M, Thiering E, Tuffnell D, Varro MJ, Vrijkotte TG, Wijga A, Wilhelm M, Wright J, Nieuwenhuijsen MJ, Pershagen G, Brunekreef B, Kogevinas M, Slama R. Ambient air pollution and low birthweight: a European cohort study (ESCAPE). Lancet Respir Med. 2013;1(9):695-704.

27. Lamichhane DK, Leem JH, Lee JY, Kim HC. A meta-analysis of exposure to particulate matter and adverse birth outcomes. Environ Health Toxicol. 2015;30:e2015011.

28. Teng C, Wang Z, Yan B. Fine particle-induced birth defects: impacts of size, payload, and beyond. Birth Defects Res C Embryo Today. 2016;108(3):196-206.

29. Urban and suburban background PM2.5 concentrations presented as 3-year averages, as an approximation of the Average Exposure Indicator from Air Quality e-Reporting (AQ e-Reporting) provided by European Environment Agency (EEA) [https://www.eea.europa.eu/data-and-maps/daviz/urban-pm2-5concentrations-as-1\#tab-chart_2] Accessed 29 June 2017.

30. Medical Birth Register, National Institute for Health and Welfare [https:// www.thl.fi/en/web/thlfi-en/statistics/information-on-statistics/registerdescriptions/newborns] Accessed 30 May 2017.

31. Register of Congenital malformations, National Institute for Health and Welfare [https://www.thl.fi/en/web/thlfi-en/statistics/information-onstatistics/register-descriptions/register-ofcongenital-malformations] Accessed 30 Oct 2017.

32. Finnish Cancer Registry [https://syoparekisteri.fi/tietoa-syoparekisterista/ yhteystiedot/] Accessed 30 May 2017

33. Care Register for Health Care, National Institute for Health and Welfare [https://www.thl.fi/en/web/thlfi-en/statistics/information-on-statistics/ register-descriptions/care-register-for-health-care] Accessed 30 May 2017. 
34. Register of Primary Health Care visits, National Institute for Health and Welfare [https://www.thl.fi/en/web/thlfi-en/statistics/information-on-statistics/registerdescriptions/register-of-primary-health-care-visits] Accessed 30 May 2017.

35. Reimbursements for Prescription medicines, Social Security Institution [http://www.kela.fi/web/en/492] Accessed 30 Oct 2017.

36. Cause-of-Death Register, Statistics Finland [http://www.stat.fi/meta/til/ksyyt_ en.html] Accessed 30 May 2017.

37. Population Register, Population Register Centre [http://vrk.fi/en/personaldata] Accessed 30 May 2017.

38. Register of Induced Abortions, National Institute for Health and Welfare [https://www.thl.fi/en/web/thlfi-en/statistics/information-on-statistics/ register-descriptions/register-of-induced-abortions] Accessed 30 May 2017.

39. Rumrich I, Viluksela M, Vähäkangas K, Gissler M, Surcel H-M, Jokinen J, Hänninen $O$. Evaluation of register study feasibility using maternal smoking as a risk factor in Finland. Proceedings of the 28th annual conference of the International Society for Environmental Epidemiology (ISEE). Rome: The Publisher is Environmental Health Perspectives (Abstract Number: P1-302 | ID: 4140). 2015. https://ehp.niehs.nih.gov/isee/2016-p1-302-4140/.

40. Männistö T, Bloigu A, Heino A, Gissler M, Surcel HM, et al. BMJOpen. 2016;6: e013296.

41. Classification of Occupation, Statistics Finland [http://tilastokeskus.fi/meta/ luokitukset/ammatti/001-2010/index en.html] Accessed 13 June 2017.

42. Finnish Maternity Cohort, National Institute for Health and Welfare [in Finnish only] [https://www.ppshp.fi/Tutkimus-ja-opetus/Biopankki/Pages/default.aspx] Accessed 30 Oct 2017.

43. Classification of Socio-economic Groups 1989, Statistics Finland [http:// tilastokeskus.fi/meta/luokitukset/sosioekon_asema/001-1989/index_en.html] Accessed 13 June 2017.

44. Prüss-Ustün A, Wollf J, Corvalán C, Bos R, Neira M. Preventing disease through healthy environments. A global assessment of the burden of disease from environmental risks. World Health Organization (WHO). 2016;

45. Carmichael SL. Birth defects epidemiology. Eur J Med Genet. 2014;57(8):355-8.

46. England L, Aagaard K, Bloch M, Conway K, Cosgrove K, Grana R, Gould TJ, Hatsukami D, Jensen F, Kandel D, Lanphear B, Leslie F, Pauly JR, Neiderhiser J, Rubinstein M, Slotkin TA, Spindel E, Stroud L, Wakschlag L. Developmental toxicity of nicotine: a transdisciplinary synthesis and implications for emerging tobacco products. Neurosci Biobehav Rev. 2017:72:176-89.

47. Laubenthal J, Zlobinskaya O, Poterlowicz K, Baumgartner A, Gdula MR, Fthenou E, Keramarou M, Hepworth SJ, Kleinjans JC, van Schooten FJ, Brunborg G, Godschalk RW, Schmid TE, Anderson D: Cigarette smokeinduced transgenerational alterations in genome stability in cord blood of human F1 offspring. FASEB J 2012, 26(10):3946-3956.

48. Langhoff-Roos J, Krebs L, Klungsoyr K, Bjarnadottir RI, Kallen K, Tapper AM, Jakobsson M, Bordahl PE, Lindqvist PG, Gottvall K, Colmorn LB, Gissler M The Nordic medical birth registers-a potential goldmine for clinical research. Acta Obstet Gynecol Scand. 2014;93(2):132-7.

49. Vahakangas K. Ethical aspects of molecular epidemiology of cancer. Carcinogenesis. 2004;25(4):465-71.

50. Ministry of Justice: Act on the Openness of Government Activities (621/1999; amendments to 907/2015 included). 2015, 907/2015.

51. Ministry of Justice: Personal Data Act (523/1999; amaendments to 986/2000 included). 2000

52. European Parliament and the Council of the European Union: REGULATION (EU) 2016/679 OF THE EUROPEAN PARLIAMENT AND OF THE COUNCIL of 27 April 2016 on the protection of natural persons with regard to the processing of personal data and on the free movement of such data, and repealing Directive 95/46/EC (General Data Protection Regulation). 2016.

53. Declaration of Helsinki; World Medical Association [https://www.wma.net/ policies-post/wma-declaration-of-helsinki-ethical-principles-for-medicalresearch-involving-human-subjects/] Accessed 30 June 2017.

54. Ministry of Social Affairs and Health: Medical Research Act (488/1999; amendments to 794/2010 included). 2010.

55. Eloranta K, Auvinen A. Population attitudes towards research use of health care registries: a population-based survey in Finland. BMC Med Ethics. 2015;16:48. doi:10.1186/s12910-015-0040-x

56. Vahakangas K. Research ethics in the post-genomic era. Environ Mol Mutagen. 2013;54(7):599-610.

57. Zhang K, Wang X. Maternal smoking and increased risk of sudden infant death syndrome: a meta-analysis. Leg Med (Tokyo). 2013;15(3):115-21.

\section{Submit your next manuscript to BioMed Central and we will help you at every step:}

- We accept pre-submission inquiries

- Our selector tool helps you to find the most relevant journal

- We provide round the clock customer support

- Convenient online submission

- Thorough peer review

- Inclusion in PubMed and all major indexing services

- Maximum visibility for your research

Submit your manuscript at www.biomedcentral.com/submit
Biomed Central 